\title{
Bioinformatic analysis of gene regulation in Geobacter sulfurreducens
} Julia Krushkal*1, Yanhua Qu1 ${ }^{1}$, Peter Brown², Sreedhar Sontineni1, Toshiyuki Ueki ${ }^{2}$, Katy Juarez ${ }^{3}$, Ching Leang ${ }^{2}$, Enrique Merino ${ }^{4}$, Jeanette Peeples ${ }^{5}$, Jose F Barbe ${ }^{1}$, Ronald M Adkins ${ }^{5}$ and Derek R Lovley ${ }^{2}$

\author{
Address: ${ }^{1}$ Department of Preventive Medicine, University of Tennessee Health Science Center, Memphis, TN 38163, USA, ${ }^{2}$ Department of \\ Microbiology, University of Massachusetts, Amherst, MA 01003, USA, ${ }^{3}$ Departamento de Ingeniería Celular y Biocatálisis, Instituto de \\ Biotecnología, Universidad Nacional Autónoma de México, Cuernavaca 62271, Mexico, ${ }^{4}$ Department of Molecular Microbiology, Instituto de \\ Biotecnología, Universidad Nacional Autónoma de México, Cuernavaca 62271, Mexico and ${ }^{5}$ Department of Pediatrics, University of Tennessee \\ Health Science Center, Memphis, TN 38163, USA \\ Email: Julia Krushkal* - jkrushka@utmem.edu \\ * Corresponding author
}

from UT-ORNL-KBRIN Bioinformatics Summit 2009

Pikeville, TN, USA. 20-22 March 2009

Published: 25 June 2009

BMC Bioinformatics 2009, I 0(Suppl 7):A9 doi:10.1 I86/I47I-2105-10-S7-A9

This abstract is available from: http://www.biomedcentral.com/I47I-2/05/I0/S7/A9

(c) 2009 Krushkal et al; licensee BioMed Central Ltd.

\section{Background}

Geobacteraceae are a family of microorganisms from the delta subdivision of Proteobacteria. They have potential for environmental bioremediation and electricity generation. In this presentation, we describe our recent bioinformatic analyses of gene regulation in Geobacter sulfurreducens, a model representative of this family.

\section{Results and conclusion}

We have developed an online database, GSEL (Geobacter Sequence Elements), which compiles regulatory information for G. sulfurreducens. We have recently completed the development of a new, significantly expanded and updated, relational version 2 of the GSEL database and its accompanying online query system, which compiles manually curated information on operon organization and transcription regulatory elements in the genome of G. sulfurreducens. GSEL v. 2 incorporates a graphical browser and provides significantly expanded search capabilities. It also includes new information on predicted and/or experimentally validated genome regulatory sites and provides links to information from microarray experiments stored in public gene expression databases, and to original publications describing how particular regulatory interactions were identified.
Using sequence and gene expression analyses, we investigated target genes and promoters regulated by RpoN, an alternative RNA polymerase sigma factor, which regulates a variety of important cellular processes in G. sulfurreducens. Our current studies are focusing on an investigation of several transcription regulatory systems involved in RpoN-dependent regulatory pathways. We have investigated target regulatory sites for an enhancer binding protein, PilR, which participates in RpoN-dependent transcriptional regulation of the pilA gene encoding structural pilin. We predicted multiple PilR-regulated sites upstream of operons related to biosynthesis, assembly, and function of pili and flagella, type II secretory pathways, and cell wall biogenesis.

We also investigated sequence changes and molecular classification of the TetR family of transcriptional regulators. In G. sulfurreducens, we identified RpoN-regulated promoters upstream of several operons containing tetR family genes. The genome of $G$. sulfurreducens contains nine tetR family genes. Some of them are located upstream of operons encoding functionally important $c$ type cytochromes. In order to better understand the roles of TetR family members in the ability of Geobacteraceae to participate in electron transfer, we investigated phylogenetic relationships among TetR proteins in Geobacteraceae 
and in other microbial species. We identified their conserved and variable domains, which may be important for the diversity of their functional roles, and classified them into subgroups based on sequence similarities.

\section{Acknowledgements}

This research was supported by the Office of Science (BER), U.S. Department of Energy, Cooperative Agreement No. DE-FC02-02ER63446.

Publish with Bio Med Central and every scientist can read your work free of charge

"BioMed Central will be the most significant development for disseminating the results of biomedical research in our lifetime. " Sir Paul Nurse, Cancer Research UK

Your research papers will be:

- available free of charge to the entire biomedical community

- peer reviewed and published immediately upon acceptance

- cited in PubMed and archived on PubMed Central

- yours - you keep the copyright 